Purdue University

Purdue e-Pubs

IMPACT Publications

Instruction Matters: Purdue Academic Course

Transformation (IMPACT)

2017

\title{
Engineering Technology vs. Engineering Students: Differences in Perception and Understanding
}

Anne M. Lucietto

Purdue University, lucietto@purdue.edu

Jennifer D. Moss

Purdue University

Eddy Efendy

Purdue University

R. Mark French

Purdue University

Follow this and additional works at: https://docs.lib.purdue.edu/impactpubs

Part of the Engineering Commons

\section{Recommended Citation}

Lucietto, A. M., Moss, J. D., Efendy, E., \& French, R. M. (2017). Engineering technology vs. engineering students: Differences in perception and understanding. In 2017 IEEE Frontiers in Education Conference (FIE) (pp. 1-7).

This document has been made available through Purdue e-Pubs, a service of the Purdue University Libraries. Please contact epubs@purdue.edu for additional information. 


\title{
Engineering Technology vs. Engineering Students: Differences in Perception and Understanding
}

\author{
Anne M. Lucietto ${ }^{1}$, Sr. Member IEEE, Jennifer D. Moss ${ }^{2}$, Eddy Efendy ${ }^{1}$, R. Mark French ${ }^{1}$ \\ School of Engineering Technology ${ }^{1}$ and the Center for Instructional Excellence ${ }^{2}$ \\ Purdue University \\ West Lafayette, IN \\ lucietto@purdue.edu
}

\begin{abstract}
Engineering technology students either are studied under the auspices of research focused on engineering students, or are excluded from engineering research in its entirety. Even when they are included in research, our understanding of engineering technology students is either missing or obscured. The lack of available research focused on engineering technology students in particular has prompted an effort to contribute to the greater body of knowledge of engineering technology education. The lack of research, as compared to other STEM fields, presents a challenge to practitioners in engineering technology programs when making discipline-specific decisions regarding these particular students.
\end{abstract}

The need to delineate and determine the differences in the engineering technology student population and that of the engineering student population has become increasingly evident to practitioners and researchers in the technology area. To explore the learning styles of the engineering and engineering technology students, the Gregorc Style Delineator was completed by students in both programs. This instrument is relatively well known and is designed to investigate how adults order their thoughts and perceive the world around them.

This study is designed to understand the differences in the engineering technology and engineering student populations by examining their mediation channels and their psychological learning styles. By furthering our conceptual understanding of both populations, we will inform those involved with teaching, curriculum development, and administration of programs how to best interact with and teach these students. Engineering technology students think differently than engineering students and that should be reflected in how we teach them.

Keywords-engineering technology; engineering; perception

\section{INTRODUCTION}

Frequently pedagogies based upon research done on the engineering student population are implemented in the engineering technology classroom [1]. Engineering education research is much more plentiful and is often used in other areas due to its availability. Practitioners in engineering technology often question the practice of using engineering education research in the engineering technology classroom. This discussion is based upon the differences noted in the students: the way they work and the approaches they use to solve problems. A fundamental understanding of the student, how they see things and work with them in their everyday lives as well as at work, is critical to how they are best taught in the formal classroom [2].

Publications focus on engineering or engineering technology students, with far fewer focusing on engineering technology [3]. The small population of students in engineering technology and the applied nature of the curriculum may contribute to the lack of published research. These authors are adding to the body of knowledge by using a proven instrument - Gregorc Style Delineator. Students in both the engineering technology program and engineering program were administered this instrument. Data from these administrations were examined for similarities and differences. The data was anonymously collected, and students were asked to answer demographic questions so the data could also be sorted during analysis.

The Gregorc Instrument [4] provides a method to study how students think in the abstract and order their thoughts. The authors chose this instrument because mediation channels used in the instrument will aide in learning each population's learning styles, allowing practitioners to understand the differences between the two groups of students, and enabling them to design better curriculum and capitalize on student strengths. This instrument was chosen due to prior work using it by one of the authors, thus being familiar with this instrument over others. Within the engineering technology practitioners there tends to be discussion regarding the differences of their students to those majoring in engineering. This work is to serve as a pilot study to determine if further work in this area is a worthwhile endeavor. 


\section{LITERATURE REVIEW}

Understanding how students perceive and make decisions supports our ability to teach and work with engineering technology and engineering students. Following a review of other instruments, it was determined that the Gregorc Style delineator reveals information desired by this study. Others have validated this method by using it in construct validation, and in comparisons to the results using the Myers Briggs survey[5]. Others have validated Gregorc and Myers-Briggs in comparison to each other since both instruments focus on the perceptions of the world and ordering of thoughts. The information obtained from the Gregorc will provide researchers with information on how these groups of students perceive the world around them and how they deal with problems.

Perception is defined as the way we gather information from our environment and interpret what it means. Gregorc breaks these things down into abstract and concrete. Concrete perception is the physical visualization of one's environment using the five senses $[6,7]$. While abstract perception is how what is seen is perceived and how one perceives things that are not seen.

Two additional aspects of this instrument include how it assesses the ability to order thoughts and information, and then make use of that information[7]. Gregorc breaks this into two components, random and sequential. Random ordering is nonlinear, and generally results in a lack of logical organization [8]. Sequential is the opposite, where information is logically arranged in an orderly manner [8].

Gregorc asserts that each human exhibits a mixture of these abilities [9]. Based on decades of phenomenological research, Gregorc [6] asserts that there are four cognitive styles. These styles aid individuals in understanding the way they interact based upon experience, their environment, and how they mediate their thoughts $[8,9]$. These styles are concrete/sequential, concrete/random, abstract/sequential, and abstract/random. See Table 1 [7].

\section{A. Gregorc-Four Cognitive Styles}

Gregorc's cognitive styles provide a unique view of how thoughts are ordered, and how we perceive our environment [10]. Considering these styles for the individual and then sorting for various demographics allows us to not only study individual students within a population, but to aggregate student data. This allows us to determine if there are commonalities within various populations studying the same curriculum. The Gregorc Instrument [11], supporting materials
[7], and other documentation $[6,8,9,11]$ provides the following information on each combination of mediation channel:

\section{1) Concrete/Sequential}

Words that describe an individual as orderly, likes to follow directions, logical, and predictable describe the person with concrete/sequential tendencies.[7] These individuals find a structured, predictable environment the easiest to deal with[8, 12].

\section{2) Abstract/Sequential}

Individuals that chose words that suggest they analyze situations before reacting to them are generally identified by Gregorc as abstract/sequential[7]. They find stimulating environments and accesses to reliable information the best environment in which to learn[8, 12].

\section{3) Abstract/Random}

The individual that identifies with abstract/random find harmonious team environments and stay on task[7]. These individuals find group work, generalized rules, and personal interaction the best working environment $[8,12]$.

\section{4) Concrete/Random}

Independent solving problems, using intuition and risk taking are all descriptive of those identifying as concrete/random[7]. Iterative, competitive environments are the best environment in which those categorized as concrete/random function[8, 12].

Further description of the Gregorc Instrument has not been included in this paper. It is a well-known instrument and is protected by copyright. Further information can be found on the Gregorc website [7] and in supporting documentation [4, 6 , 11]. Prior work comparing different learning style instruments was done by James and Blank [13], this includes a caution regarding use of any instrument - it should be used with care and for the appropriate age group. This instrument measures preferences, and is intended for use with adults. For this pilot study, it appears appropriate and consistent with the comparison described in this paper.

\section{RESEARCH QUESTIONS}

This effort to further our understanding of the differences between the engineering and engineering technology student populations has raised a number of questions. Engineering and engineering technology students are different. Many instructors teach in the manner they were taught, and in the case of engineering technology students this may be problematic. Learning more about the mediation channels that 
are prevalent in each group will help establish a framework of successful pedagogies for each population. It will also provide guidance in research focused on identifying population differences in these two groups of students. The questions developed for this part of our study are:

- What combination of mediation channels are found in engineering technology students and engineering students?

- How do the mediation channel combinations compare between engineering technology and engineering students?

- What differences in pedagogies when teaching engineering technology students vs. engineering students should exist based on Gregorc's findings?

\section{METHODS}

To answer these questions with the smaller test populations, inferential statistics using SPSS [14] was used to assess the administration of the Gregorc Instrument. The researchers had 156 Engineering Technology and 180 Engineering students available for this sample.

\section{A. Data Collection}

The instrument, The Gregorc Style Delineator[6], features sets of four words where each word indicates one of the four particular learning styles. The exact words are proprietary, but overall, the words describe particular traits such as thoughtfulness and rashness. Students ranked each of the words in a set from 1 to 4 . The students were asked to use their first impressions of the words to guide their ranking. There are ten sets of words and, in a particular mediation channel, students could earn from 10 to 40 points[15].

The students were given the Gregorc Instrument in the Fall 2016/Spring 2017 semesters. All administrations were completed within a 12 week span. Students were told that they do not have to complete these instruments, however after an explanation of this project, all participated. Instruments were purchased and students were asked to complete them.

\section{B. Data Analysis}

The data was entered into Excel and columns tallied per the instructions on the instrument ${ }^{8}$. Individual as well as aggregate information is available for this entire group of students. Comparisons were made between aggregate data taken from both engineering technology and engineering students. Further analysis, including independent sample t-tests, were conducted in SPSS [14].

\section{Individual vs. Aggregated Data}

This instrument was designed for the individual, providing them with an understanding of their own preferences. The authors found that aggregating the data provides a different view of the students at large. While others have supported and refuted this approach for a variety of reasons [16, 17], the studied populations are small enough to review aggregated data and the identification of mediation channels. This methodology provides a detailed review of students in this population. Until further work on this project is completed and findings indicate otherwise, understanding the student using this methodology appears to be appropriate [18, 19].

\section{FINDINGS}

There were 180 Engineering students and 156 engineering technology students in the combined sample. The engineering technology sample did not include gender or race/ethnicity, so it was unable to calculate any comparisons other than year in school and program of enrollment.

A. Comparison of Aggregate of Engineering Technology Students to Engineering Students

\section{1) Concrete/Sequential}

For concrete/sequential, there was no statistical difference, $p>.05$. The mean difference between the two groups was .0038 , indicating that the two groups were not only not significantly different, they were nearly identical. This means that engineering technology students and engineering students are alike in their concrete/sequential perception and ordering of thoughts. This mediation style indicates that both student groups like order, logical sequencing of information, and working in a structured environment [7].

\section{2) Abstract/Sequential}

For abstract/sequential, there was also no statistical difference, $p>.05$. In this case, the mean difference is .2248 , which is also quite similar, with less than a quarter of a point differentiating the groups where the groups' totals are 26.039 and 25.814. This indicates that both study populations of engineering technology students and engineering students are alike in Gregorc's abstract/sequential mediation channel. Both groups like their points to be heard, analyze situations before acting on their response, and like to be in stimulating environments[7]. 


\section{3) Abstract/Random}

For abstract/random, there was also no statistical difference. The $\mathrm{p}$ value is greater than .05 . Again, the two groups are nearly identical with a mean difference less than .5, at .4769. This means that in this mediation channel engineering technology students and engineering students are alike. They both do not like disorder and random thoughts in their environment [7].

\section{4) Concrete/Random}

For concrete/random, there was a statistically significant difference. The $\mathrm{p}$ value is .019 , which is statistically significantly different at the $\mathrm{p}<.05$ level. The mean difference is 1.2205 . This means that the engineering and engineering technology students process differently along this dimension. The mean concrete/random score for the ET students was 26.571 and the mean score for concrete random for the engineering students was 25.350 . While the numbers seem similar, the engineering technology students scored higher here, indicating that engineering technology students tend to use intuition more than their colleagues do in engineering to solve problems. They also prefer independent problem solving, and are more willing to take risks than engineering students.

\section{B. Overall Comparison of Student Populations}

In the previous section, student groups were compared using statistical techniques. Comparing these same groups by the mean difference is shown in Figure 1 below.

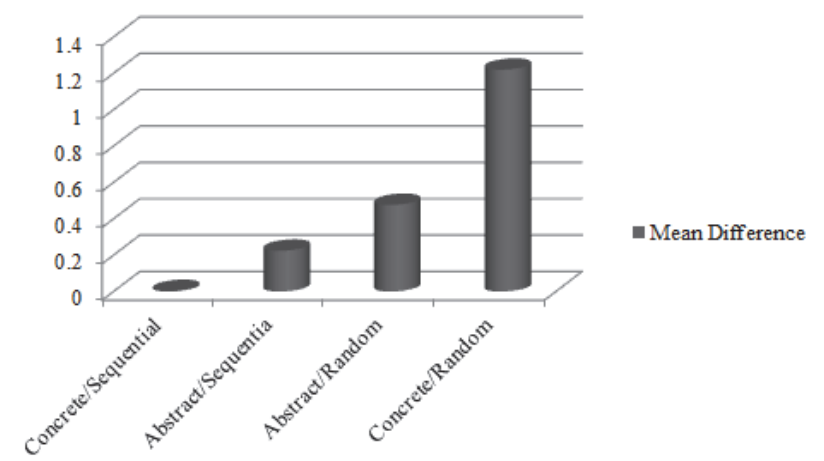

Figure 1. Mean Difference Between Student Populations

This figure provides a visual comparison, clearly providing a guide to the differences in engineering and engineering technology student groups.

Engineering technology students study similar topics to engineering students, however, their work is presented using applied learning techniques. This comparison provides practitioners at this university confirmation that the study group of engineering technology student's desire to use iterative processes to solve problems. They also prefer independent problem solving over their engineering counterparts who thrive in group problem solving settings. Based on the information gathered in this limited study, engineering students are comfortable using their intuition to solve problems and take risks in their work.

In all other aspects of this comparison, the differences are rather small. It should be noted, that while both student groups process similarly in the abstract/random mediation channel there was a greater difference in this area than the other mediation channels. Thus documenting that there is a difference in engineering technology and engineering students in their tolerance of disorder and random thoughts in their environment. With the engineering technology students more tolerant of both conditions.

\section{DISCUSSION}

The findings provide an interesting perspective of the differences between engineering technology and engineering students. When comparing the aggregate of freshman and senior engineering technology students to freshman and senior engineering students we find them significantly different in the concrete/random mediation channel. Engineering technology students rate this area much higher than engineering students do. This analysis shows that there is little difference in the other three mediation channels.

Concrete/random shows a statistically significant difference in engineering technology students and engineering students. While reviewing the concrete/random description [7], it states that the learner prefers experimenting to find answers, uses intuition, and solves problems independently. Since engineering technology students scored significantly higher than engineering students, we can suggest that engineering technology students learn best when using iterative or trial and error approaches to problem solving, and they prefer to work through problems by themselves and compete with those doing a similar/same thing. They do not like formal reports, redoing anything once they have finished it, keeping detailed records, and showing how they got an answer. These results provide answers to the first and third research questions. They also further our understanding of the differences between engineering technology students and engineering students, providing insights into the preferences of engineering technology students and their preferences in the learning environment by scoring higher on the concrete/random mediation channel. 
The second question considers the contrast of mediation channel combinations. The findings section describes the mediation channels, other than concrete/random, as very similar between the two student populations. There is little difference in the combination of mediation channels other than the preferences of students in the concrete/random category.

Students at this university matriculate into engineering technology, engineering, another field, or drop out of the university entirely. The most common path to engineering technology is freshman or sophomores that transfer to engineering. These transfers happen for a multitude of reasons including: engineering was too theoretical; grades in engineering were not good; engineering was nothing like what they thought it was. Figure 2 below shows the generalized movement of students occurs between programs from freshman to senior year.

Given the results of the first analysis, the fact that the concrete/random mediation channel is so different from one student population to another in the aggregate analysis suggests that those freshman students first matriculating in engineering skew the data enough that there is no difference in the aggregate comparison.. Using Gregorc's criteria [7], the results of this comparison suggest that engineering technology students prefer taking risks, using their intuition, and working independently.

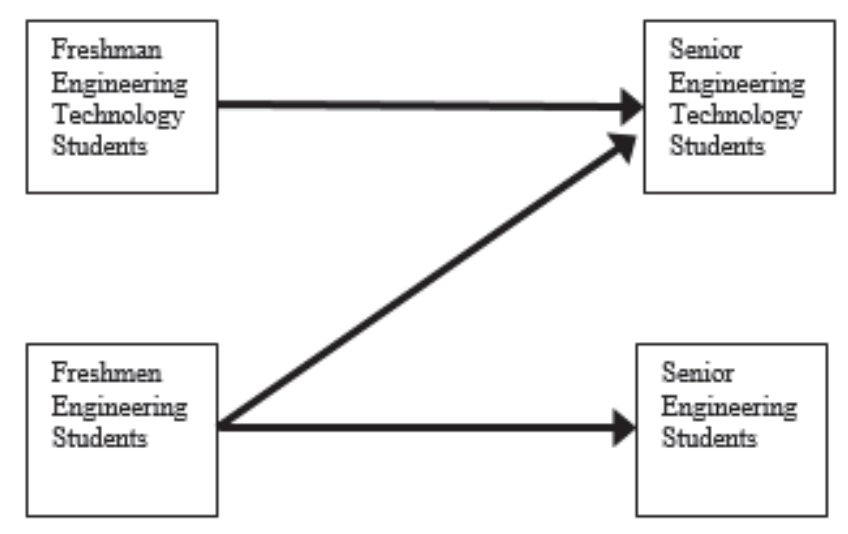

Figure 2. Generalized Movement of Students Year to Year

\section{CONCLUSION}

The similarities between the combinations of mediation channels suggest that students in both populations exhibit similar combinations of preferences, and find similar things difficult for them. While reviewing the data, the results suggest that students in these two groups vary in their ability to work in teams, compete, multi-task, and deal with details. These are all things that may influence how students look at situations and deal with technical problems. Understanding this provides a means by which one or the other from the different majors learns and how they work with others. It also provides suggestions for pedagogy development as the difference in preference for independent problem solving and iterative methods to solve problems require different approaches to teaching and learning for engineering technology students. 


\section{REFERENCES}

[1] A. M. Lucietto and E. Efendy, "Systematic Review of Engineering Technology Education Literature," in ASEE's Annual Conference \& Exposition, New Orleans, LA, 2016.

[2] P. Bell, Ed., Lewenstein, Bruce, Ed., Shouse, Andrew W., Ed., \& Feder, Michael A., Ed., Learning Science in Informal Environments: People, Places, and Pursuits. . Washington, DC, 2009.

[3] K. G. Frase, R. M. Latanision, and G. Pearson, "Engineering Technology Education in the United States," National Academies Press, Washington, D.C.2016.

[4] A. F. Gregorc, Gregorc style delineator: A selfassessment instrument for adults: Gregorc Assoc., 1985.

[5] D. W. Salter, N. J. Evans, and D. S. Forney, "A longitudinal study of learning style preferences on the Myers-Briggs type indicator and learning style inventory," Journal of College Student Development, vol. 47, pp. 173-184, 2006.

[6] A. F. Gregorc, An adult's guide to style: Gregorc Associates Columbia, Conn, 1982.

[7] A. F. Gregorc. (2016, March 28). Mind Styles Anthony Gregorc. Available: http://web.cortland.edu/andersmd/learning/Gregorc.h $\underline{\mathrm{tm}}$

[8] A. F. Gregorc, "Learning/teaching styles: Their nature and effects," Student learning styles: Diagnosing and prescribing programs, pp. 19-26, 1979.

[9] A. F. Gregorc, "Style as a symptom: A phenomenological perspective," Theory into practice, vol. 23, pp. 51-55, 1984.

[10] T. F. Hawk and A. J. Shah, "Using learning style instruments to enhance student learning," Decision
Sciences Journal of Innovative Education, vol. 5, pp. 1-19, 2007.

[11] A. F. Gregorc, Gregorc Style Delineator: Developmental technical and administration manual: Gregorc associates Incorporated, 1984.

[12] A. F. Gregorc and H. B. Ward, "A new definition for individual," Nassp Bulletin, vol. 61, pp. 20-26, 1977.

[13] W. B. James and W. E. Blank, "Review and critique of available learning-style instruments for adults," New Directions for Adult and Continuing Education, vol. 1993, pp. 47-57, 1993.

[14] IBM Corporation, "IBM SPSS Statistics for Windows (Version 22.0)[Computer software]," ed: IBM Corp Armonk, NY, 2013.

[15] S. A. Watson, "Learning styles of interior design students as assessed by the Gregorc Style Delineator," Journal of Interior Design, vol. 27, pp. 12-19, 2001.

[16] G. King, A solution to the ecological inference problem: Reconstructing individual behavior from aggregate data: Princeton University Press, 2013.

[17] V. I. Sessa and M. London, Continuous learning in organizations: Individual, group, and organizational perspectives: Psychology Press, 2015.

[18] C. H. Kennedy, Single-case designs for educational research: Prentice Hall, 2005.

[19] M. M. Kennedy, "Generalizing from single case studies," Evaluation Review, vol. 3, pp. 661-678, 1979. 
Table 1. Mind Styles - Anthony Gregorc ${ }^{7}$

CONCRETE SEQUENTIAL

This learner likes:

- order

- logical sequence

- following directions, predictability

- getting facts

They leam best when:

- they have a structured environment

- they can rely on others to complete the task

- are faced with predictable situations

- can apply ideas in pragmatic ways

What's hard for them?

- working in groups

- discussions that seem to have no specific point.

- work in an unorganized environment

- following incomplete or unclear directions

- work with unpredictable people

- deal with abstract ideas

- demands to "use your imagination"

- questions with no right or wrong answers

\section{ABSTRACT SEQUENTIAL}

This leamer likes:

- his/her point to be heard

- analyzing situations before making a decision or acting

- applying logic in solving or finding solutions to problems

They learn best when:

- they have access to experts or references

- place in stimulating environments

- able to work alone

What's hard for them?

- being forced to work with those of differing views

- too little time to deal with a subject thoroughly

- repeating the same tasks over and over

- lots of specific nules and regulations

- "sentimental" thinking

- expressing their emotions

- being diplomatic when convincing others

- not monopolizing a conversation

\section{CONCRETE RANDOM}

This learner likes:

- experimenting to find answers

- take risks

- use their intuition

- solving problems independently

They leam best when:

- they are able to use trial-and-error approaches

- able to compete with others

- given the opportunity to work through the problems by thernselves

What's hard for them?

- restrictions and limitations

- formal reports

- routines

- re-doing anything once it's done

- keeping detailed records

- showing how they got an answer

- choosing only one answer

- having no options

\section{ABSTRACT RANDOM}

This leamer likes:

- to listen to others

- bringing harmony to group situations

- establishing healthy relations with others

- focusing on the issues at hand

They learn best when:

- in a personalized environment

- given broad or general guidelines

- able to maintain friendly relationships

- able to participate in group activities

What's hard for them?

- having to explain or justify feelings

- competition

- working with dictatorial/authoritarian personalities

- work in a restrictive environment

- working with people who don't seem friendly

- concentrating on one thing at a time

- giving exact details

- accepting even positive criticism 